\title{
Relationship dynamics and sexual risk behaviour of male partners of female sex workers in Kampala, Uganda.
}

Martin Mbonye ${ }^{1}$, Godfrey Siu ${ }^{1,2}$, Thadeus Kiwanuka ${ }^{1}$, Janet Seeley ${ }^{1,3}$

Affiliation

1. MRC/UVRI Uganda Research Unit on AIDS, Entebbe, Uganda

2. Makerere University, Kampala, Uganda

3. London School of Hygiene and Tropical Medicine, London, UK

\begin{abstract}
Male regular partners of female sex workers represent an important population to reach with HIV-prevention interventions. In this paper we discuss the relationship dynamics and HIV/STI risk behaviour of men involved with self-identified female sex workers (FSW) in Kampala. Between 2011 and 2014 we conducted repeat in-depth interviews with 42 male partners of FSWs attending a clinic for women at high risk of HIV-infection in Kampala. Men publicly struggled with the stigma of dating women who are considered to be engaged in a shamed profession, but privately saw meaning in these relationships. In coping with the stigma, some described the work of their partners in terms that distanced them from sex work, while others struggled to have the control that 'being a man' demanded since they could not monitor all movements of their partners. Dealing with HIV disclosure was hard, and seeking support difficult for some of the men leading to missed opportunities and guilt. Despite challenges, relationships with sex workers offered men some benefits such as access to much needed care and treatment. A few men also admitted to being motivated by material and financial benefits from sex workers who they perceived as being rich and this was one factor that helped them sustain the relationships. These findings offer insights into the complex relationship dynamics within high risk sexual partnerships but the findings suggest that effective interventions that are couple centred can be established to promote better health.
\end{abstract}

Key words: Relationship, Male partners, Sex workers, Respectability, Reputation Disclosure 


\section{Introduction}

Commercial sex work is a major public health concern in settings with high HIV prevalence. In such settings female sex workers (FSW) and their clients are at greater risk of HIV and other sexually transmitted infections than the general population (Baral et al., 2012; Scorgie et al., 2012), due largely to inconsistent condom use with multiple sexual partners, including with the regular partners (Rekart, 2006; Vanwesenbeeck, 2001; Wojcicki \& Malala, 2001). Reaching sex workers and their clients can therefore significantly contribute to global efforts to fast track HIV prevention and treatment (UNAIDS, 2014). Interventions targeting male partners of sex workers offer an opportunity to address the risk associated with this sub-population. However, male clients are rarely reached (Fleming et al., 2015; Jackson et al., 2009; Kerrigan et al., 2015; Syvertsen, Robertson, Palinkas, et al., 2013; Syvertsen, Robertson, Rolón, et al., 2013) and the stigma associated with sex work and masculinity drives such men underground, with negative consequences for both themselves, their partners and efforts to fast track HIV prevention.

In many settings, female sex workers depend on paying clients for their livelihood. As a commercial arrangement, a stable client base may be the best way of sustaining a regular income. However, as a man becomes a 'stable client' he may develop deeper intimacy with a sex worker and become a regular partner. Indeed, one motivation for seeking commercial sex is a desire for intimacy as well as companionship (Vanwesenbeeck, 2001) and as intimacy levels grow, so do the ties of the relationship (Sanders, 2008). The boundaries between sex work and other forms of sexual partnerships can become blurred when a man becomes a regular partner. Such relationships are shaped by dominant masculine norms which place the man firmly in control. The desire for greater sexual pleasure or children, and the concern to validate trust in a relationship means that condom use is forgotten in these sexual relationships, resulting in an increased risk of HIV-infection (Aho, Koushik, \& Rashed, 2012; Goldenberg et al., 2010; Matovu \& Ssebadduka, 2014; Murray et al., 2007; Rutakumwa et al., 2015).

In this paper we discuss the narratives of men who have developed intimate relationships with women at high risk of HIV and STI, including sex workers. We 
document relationship dynamics and risk perceptions of the men and how they make meaning out of their relationships with self-identified FSWs in Kampala. We highlight issues that may hinder or facilitate the fast tracking of the HIV prevention agenda specific to this population.

\section{Theoretical framework: sexuality, masculinity and sex work}

In every society men and women have different roles and behaviours, which shape in many different ways, their opportunities and vulnerabilities (Jewkes \& Morrell, 2010). Although the pattern of gender relations is changing, in some societies there are still many universal conventional roles and norms that women and men are expected to conform to in sub-Saharan Africa. In Uganda, for example, women are seen as home makers, perform household chores, submissive to males, especially their partners, and are expected to be economically dependent on men, while men are responsible for material provision, are decision makers, are family heads, and are expected to have multiple sexual partners (Beohut-Betts, 2005; Cornwall, 2005; Nyanzi, NyanziWokholi, \& Kalina, 2008; Siu, Seeley, \& Wight, 2013; Wyrod, 2008).

Such gender inequalities mean that men as a 'group' tend to enjoy more privileges than women as a 'group' (Kimmel, 2001), and this significantly shapes men's and women's perception of their sexuality and relationships (Wolff, Blanc, \& Gage, 2000). While men can almost uncomplicatedly express their masculinity through multiple sexual partners and control of a partner's sexuality, women are expected to be sexually inhibited, subordinate and faithful to one partner (Barker \& Ricardo, 2005). Sex work therefore contradicts the established sexual norms of women and poses particular challenges for both the women involved in it, as well as the men who pay them for sex or establish intimate relationships with them. What dilemmas and challenges to their masculinity do men who establish regular sexual relationships with sex workers experience? Why do some men sustain such relationships?.

We suggest that the experiences and dynamics of men's sexual relationships with sex workers may be examined using concepts of reputation, respectability, empowerment and disempowerment. Masculine respectability can be seen as the social worth of a man accruing from proper attention to the requisites of marriage and providing for children, consistent hard work and adequate material possessions, as affirmed by the family and wider society, including religious institutions. Reputation is the honour 
accrued to a man as a result of his masculine activities, such as sexual prowess and competition, as perceived almost entirely by male peers and sexual partners (Siu, Seeley, \& Wight, 2013).

Maintaining multiple concurrent sexual partners is one way men reinforce their reputations (Jewkes, Sikweyiya, Morrell, \& Dunkle, 2011), but respectability and reputation reflect contrasting moralities and dilemmas over men's sexuality. How does engagement with sex workers affect the men for whom privilege, power and control of sexual situations and relationships with women is usually a normative expectation? To what extent is it empowering or disempowering?

\section{Methods}

Setting

The study was conducted in Kampala, Uganda between 2011 and 2014 at a clinic of women attending a high risk epidemiological cohort in Kampala: the Good Health for Women Project (GHWP). The cohort was established in 2008 for research and provision of care services. Women were identified from sex work spots in Kampala, recruited, followed up, and offered treatment for HIV, STIs and other selected diseases. Following the establishment of the provision of care to women, the clinic later was expanded to include their male partners. Women were accordingly invited to ask their regular male partners if they would also like to receive care. When a man accepted this invitation an appointment was set with the study mobilizers to discuss attendance in the clinic. By 2014 about 100 male partners were attending the clinic.

\section{Data collection}

We interviewed 42 of the 100 men attending the GHWP at the time. The men were sampled by approaching those attending the clinic and asking if they wished to participate in a series of in-depth interviews. The men who were interested were then briefed about the purpose of the study and offered a copy of the study information sheet to help inform their decision to take part. Those who had voluntarily consented were invited to the GHWP clinic and interviewed in private, by a male interviewer familiar with qualitative methods and the local language. In a few cases, interviews were conducted at another location suitable to the interviewee. Each man was 
interviewed more than once (maximum of three times) using a semi structured life history interview guide that focused on early life through to current experiences that shaped their sexual behaviours. The subsequent interviews allowed the interviewer to clarify and probe important themes.

Interviews were mostly conducted in Luganda, a widely spoken language in central Uganda. As was the agreed practice at the GHWP clinic, interviews were not audio recorded because of concerns expressed by women and men participating in research at the clinic about recordings. Detailed notes taken during interviews were typed out immediately after the interview, paying careful attention to including verbatim quotes where possible.

\section{Data analysis}

Analysis was an iterative process. Key impressions and preliminary themes were generated by consensus by the social science team (MM, GS, TK and JS) following a detailed debriefing and discussion. Any points of contention were resolved by seeking clarification from the participant in the subsequent interviews. Any emerging theme related to relationship dynamics between these men and their partners was probed further in later interviews. Once the coding framework was agreed, manual coding was undertaken by MM and TK, with the aid of excel sheets and following the principles of thematic analysis (Braun \& Clarke, 2006). Data are presented using pseudonyms.

The study was reviewed and approved by the Uganda Virus Research Institute Science and Ethics Committee as well as the Uganda National Council for Science and Technology (SS3071). Each participant received a transport and time reimbursement of Uganda Shillings 10,000 (3 USD) every time they were interviewed.

\section{Findings}

\section{Sample characteristics}

The men participating in the study were aged between 19 and 57 years. Most were engaged in informal industry such as commercial motorcycle riders (locally known as boda boda), builders, and long distance truck drivers. Close to three quarters of the sample had attained only primary level education and tended to blame their poor parents for the inability to continue beyond that otherwise low level of education. Some 
blamed this for their inability to command a stable well-paying salaried job. Mobility and short term contracts are a feature of the type of employment that they reported, and this in part, was given by the men interviewed as the reason for maintaining sex partners in different places. None of the men was formally married to the sex worker partner, a few had visited the families of their partners to introduce themselves, something that seemed to be the equivalent of marriage to most of the men. Two of the men were in the process of trying to secure their female sex worker partners' alternative jobs, then 'marry' them. However, nearly all the men had more than one partner. The majority of the men had had a child, many as early as during their school days. While some men currently lived with their children, most had either left that responsibility to the mothers of those children, or had sent them to live with a relative. Although this was not asked, during the interaction with these men, 18 of the 42 men disclosed that they were HIV positive.

\section{Perception of relationships with sex workers: creating a public distance yet staying close privately}

Men did not feel comfortable that they were in a sexual relationship with a woman who could be described as a sex worker, despite their accounts about how they met and their knowledge of the circumstances of the women, suggesting that they were engaged in sex work. Nearly all the men met their partners in bars or other popular hot spots for sex work. The men presented a different picture or identity of the women with whom they were now in a regular relationship. They used phrases that did not directly identify or refer to their partners as sex workers, despite being aware of their work. In some cases, the men feigned ignorance, portraying a more positive or socially acceptable public image of those women. Jackson (aged 32, a commercial motorcyclist-also locally popularly known as boda boda) described his partner:

She told me that she works in a bar and I don't spy on her since she works at night and comes back at around 01:00 am. I don't know what she does; perhaps she is a sex worker but that's her business. But she cares a lot about me, gives me food to eat and we then have sex.

Fred, a 33 year old disc jockey admitted that his partner was a sex worker, but even then, he too did so indirectly, saying: 'Almost all women who work as bar attendants are sex workers. If a man goes to a bar and he needs a sex worker, he can tell a bar 
maid to trace one for him. However, the bar maid can ask him if she is not a woman [meaning that why should he ask for other women yet she is also available]...they do not want to be called sex workers, they pretend that they work in saloons, bars or lodges.'

The failure to directly acknowledge that their partners were sex workers, in spite of being aware that their sex lives betrayed this identify, helped distance these women from sex work, and preserved a man's positive self-image/dignity as they dealt with their feelings about the relationship.

Some men articulated a discourse of shame associated with being in a relationship with a sex worker. This affected their own self-image as a provider, and respectable partner, in turn resulting in low self-esteem. Mark, 40 years, a commercial driver, for example, was aware that his partner was a sex worker, but he consoled himself by saying that he made use of her to support himself and did not live with her. He said:

...I think I am so hard hearted. I used to call her and asked her for about 100,000/and she would send it, ask for another 50,000/- and she gives it to me and the good thing we don't stay together.

Nevertheless, in spite of the shame associated with these relationships, some men maintained a close private relationship and (like Mark above) identified some benefit from the relationships. Unlike other sexual partners of these men, most of the sex workers were described as 'development minded', earning their own money and not being entirely dependent on the man:

...this woman I settled down with was one of the many I had moved out with. I decided to settle with her because at least she was doing something and she appeared to be understanding, plus she was developmental. We started staying together but I still moved out with other women secretly due to the influence of alcohol (Tony, age 29, market vendor).

Indeed, we found that some men had been attracted to start relationships with sex workers because they expected to benefit from the high income that these women earned from sex work. An added bonus was that the men could freely relate with other sexual partners without being questioned. Ben (aged 27, market vendor), was an example of this: 
It was in 2005 when I got this woman... She used to give me many things, like money and could take good care of me, and I also loved her a lot because of her beauty. This same woman also had her own home in a Kampala suburb where I used to spend nights with her. She doesn't have any other job [apart from sex work] and she is free with it. I also always get other girls for sex when she is also out doing her work.

Men also recounted health related benefits that accrued from their current relationship with sex workers who had free access to HIV health services and information: Geoffrey said:

I was introduced to the clinic by a girlfriend I had got from sex work. I used to pay her for sex for some long time which later became a regular relationship and she then brought me to this [GHWP] clinic.

\section{The myth of faithfulness/trust: vulnerability and uncertainty}

The men involved in sexual relationships with sex workers recounted a range of health risks and physical violence, resulting in a narrative of vulnerability, fear, victimhood and a discourse on the uncertain nature of being a partner of a sex worker. All the men reported some worry about women in multiple sex relationships, and what those women were capable of doing or saying. Most described their partners as "tricky", "exploitative", "manipulative" or "outspoken." Others described difficulty controlling their sexuality and decisions to get new partners, sexual negotiation and use of condoms, suggesting women dictated the terms of the relationship. This was especially so among the women who had multiple relationships when they travelled for their work:

...women are easily changed by a very small thing [implying the potential to engage in paid sex] and so when she returns from Juba [capital of the Republic of South Sudan], I tell her to come and test at the clinic. (Simon aged 34 years, metal workshop owner)

In addition, some men's accounts also portrayed a precarious sense of anxiety and feelings of powerlessness over protecting themselves from the risk of HIV infection. For example, Reagan aged 42 and currently unemployed, was caught in a dilemma over the risk of unprotected sex with his HIV-positive partner and his desire for a child. Pressure from her to drop condom use was not helping the situation: 
She has sometimes asked me why we don't have sex without a condom like in the past before I got to know her status. I don't want to get infected, she also said that she will never get another man to settle down with because I had been so soft with her, I don't beat her or even pick a fight with her. The truth is, I would like to have a child and the counsellor said that it is possible. My problem is my poor financial status, I can't take care of a pregnant woman.

Another man, Stuart, 31 years old, who sells perishable foods in a suburban market expressed similar challenges initiating and/ or maintaining protected sex with his HIV positive sex worker partner because he wanted a child with her:

When you get so intimate, you tend to forget that what you are doing is wrong. It is because I wanted to have another child with this woman that I don't use the condoms consistently much as we know the risk, but we have nothing to do.

Men's knowledge of the nature of sex work, the activities involved, and the company that such women maintained with several men or women of 'questionable' character led men to feel powerless or incapable of exerting control over them as they would in a relationship with a woman not engaged in sex work. They reported that, even if one wished to, it was difficult to trust a woman of this calibre and in some cases, it was pointless or even futile to try to do so. For instance, Fred (age 36, builder) narrated:

In terms of trust I rate her at $20 \%$. This is because she moves a lot and she is friends with a clique of women who hop from bar to bar even during the day. These women cannot let her settle down. What I do is to find my own way of moving out also.

\section{The challenges of HIV status disclosure}

Dealing with HIV status disclosure was something that was likely to happen in the context of these relationships, given the high risk behaviour that was a feature of both partners' lives. It was not unusual that these men had more than one partner and in many cases the sex worker partner was not the primary partner. Some of the men therefore who knew that they were HIV-positive, and who might have blamed the sex worker partner for the infection, felt guilty about informing their primary partner. This guilt for instance forced Vincent to disclose to the other wife resulting in consequences that he was not prepared for: 
I had tried to look for a way of telling my other wife about my status but had failed. My wife trusted me a lot and I didn't know how to start. I had expected her to have acquired the virus because we have been together for a long time. [...] I was also advised to bring my first wife and test at the clinic but luckily enough she was found HIV negative. But sometimes I regret asking her to test because she now denies me sex and only offers rarely out of pity for me!

The shame and guilt of being involved in a relationship with a sex worker and apparent confusion about the status of the relationship also influenced men's preparedness to disclose their HIV infection to their sex-worker partners. The narratives showed that disclosure was characterised by concerns about blame and fear of unknown consequences for the relationship. Resolving this dilemma was not straight forward and many men struggled with it. In Gregory's case, he seemed to devise a plan to blame her to avoid having to let her know that he knew that he was HIV-positive:

...it was in 2010 when I got to know about my status, I had started to suffer a lot of illnesses that were not recovering and so I went to hospital took an HIV test which returned HIV positive. I trembled and got worried but later, I said that's life and started taking drugs. I blame one woman that I moved out with but later found her with some other man. On return from western Uganda I got another wife [female sex worker], but never told her about my HIV status and yet we were having sex without a condom all along. I had a stomach problem every time I had sex with her so decided to blame her and told her to go for a test. In early Jan 2014, my wife was counselled and tested and found HIV positive. (Gregory, 31 year old former soldier, now a commercial motorcyclist/boda-boda)

\section{Discussion and conclusion}

We have explored the relationship dynamics of male partners of FSWs in urban Kampala, and described the context in which those relationships emerged. The sample was quite small, and specific to a self-select group who agreed to the invitation to take part in the interview. This limits the generalizability of results to other male partners of sex workers. However, this qualitative study focuses on a unique population that is rarely studied, and contributes important insights which could broaden the HIV prevention agenda. 
Relationships with sex workers were characterised by men tending to distance themselves from sex work in the public sphere. Sex work is a shamed profession (Mahajan et al., 2008), and disguising one's relationship with sex workers may protect a man's respectability which is predicted on being a faithful partner (Siu, Seeley, \& Wight, 2013). HIV prevention messages that emphasise faithfulness in marriage have been reported to inadvertently contribute to new forms of sexual secrecy in Uganda (Parikh, 2007). However, the men in this study sustained relationships with the sex workers due in part to the health related (access to the clinic the women in our study attended) and financial benefits that accrued, as well as affection for their partner. This was a departure from the conventional male provider role, and starkly contradicted the normative expression of masculinity through that role (Harrison et al., 2006). Economic disempowerment of men and women's greater role in providing for the family undermines masculinity (Silberschmidt, 2001). This has been documented among men living with HIV in Uganda (Siu, Wight, \& Seeley, 2014; Wyrod, 2011). Our study shows how men relinquish some of their masculine power in favour of financial benefits from FSWs while maintaining relationships with other women with whom they can exercise their masculine privileges. This sort of compensation is also a recipe for high risk sexual behaviour as it sustains multiple partnerships. Sex workers themselves in trying to win the trust of male partners may offer their hard earned finances to them hoping to earn it back through sex work which may include further risk taking behaviour. In relationships such as these, sexual risk taking is common, the subject of HIV status disclosure becomes prominent. We saw how a number of our participants delayed or avoided disclosure despite having had prior knowledge and expressed willingness to inform their partners, including those who were not sex workers and who might have been the primary partners. An important point to note was that these men showed a caring attitude but struggled with the decision to disclose to partners who they could have regarded as innocent victims and possibly protected from HIV infection. The guilt, shame and fear of negative consequences associated with HIV status disclosure have been highlighted before (Simbayi et al., 2007). This suggests the need for assisted and timely disclosure to take advantage of the good will that seems to exist (Kalichman et al., 2007).

Establishing trust within the established relationship with a sex worker was very challenging, a finding that has been reported elsewhere (Bellhouse, Crebbin, Fairley, 
\& Bilardi, 2015). However, within this complex context, couples found ways of coping with the challenges. The men tried their very best to mask the identities of the occupations of the women or claimed to be ignorant about what the women did even if they suspected that they were engaged in sex work. Sex workers themselves in trying to draw boundaries between their relationships with regular partners and clients have been known to develop coping mechanisms including creating barriers and removing them depending on which partner they were engaged with at any given time (Syvertsen et al., 2015; Syvertsen, Robertson, Palinkas, et al., 2013; Warr \& Pyett, 1999).

Expressions of love in many societies include the provision of gifts by the man (Wamoyi et al., 2011). Most of the men in this study may have begun their relationship as paying clients, but as the relationship deepened they often provided some form of regular support (paying house rent or other contributions) as partners do in noncommercial settings. This was a part of building trust in the relationship; something which was particularly challenging in the context of multiple partners. Exclusive sexual access that is a desired feature of monogamous relationships was extremely hard to achieve given the type of work done by the female partners, a finding that resonates with research on women working in the same or similar types of work and the challenges it presents to their relationships (Bradley, 2007). Having a child was an important consideration in these relationships which made condom use very hard to sustain even in the context of HIV sero-discordant relationships. Therefore, attending the clinic was important as they had access to a variety of HIV prevention options.

In conclusion, while many challenges exist within relationships between men and sex workers described in this paper, opportunities to nurture stability and negotiate safer sex exist. Men, through the support and encouragement of their FSW partners were able to access health care, with some starting much needed antiretroviral drugs. Others were taught about combination HIV prevention, for example through 'Test and Treat' as well as referrals for safe male circumcision. Structural interventions that exploit the opportunities to intervene within these populations at high risk of infection and that challenge negative masculine norms can be designed with a better understanding of the dynamics that enhance the high risk behaviours. Norms that reinforce masculine reputation such as having several partners play a crucial role in heightening HIV risk behaviour. These need to be targeted through peer-led 
approaches as well as other methods that are gender sensitive. These findings offer an opportunity to understand relationship dynamics between two categories of high risk groups who are trying to get by as man and wife. Male partners of FSWs, are important players in the risk dynamics that the sex workers face on a regular basis. The fear that men who are regular partners of female sex workers are hard to reach can be overcome by encouraging them to access testing, counselling and treatment through their partners.

\section{References}

Aho, J., Koushik, A., \& Rashed, S. (2012). Reasons for inconsistent condom use among female sex workers: need for integrated reproductive and prevention services. World Health and Population, 14(3), 5-13.

Baral, S., Beyrer, C., Muessig, K., Poteat, T., Wirtz, A. L., Decker, M. R., Sherman, S. G., \& Kerrigan, D. (2012). Burden of HIV among female sex workers in lowincome and middle-income countries: a systematic review and meta-analysis. The Lancet Infectious Diseases, 12(7), 538-549.

Barker, G., \& Ricardo, C. (2005). Young men and the construction of masculinity in sub-Saharan Africa: implications for HIVIAIDS, conflict, and violence: World Bank Washington, DC.

Bellhouse, C., Crebbin, S., Fairley, C. K., \& Bilardi, J. E. (2015). The Impact of Sex Work on Women's Personal Romantic Relationships and the Mental Separation of Their Work and Personal Lives: A Mixed-Methods Study. PLoS One, 10(10), e0141575.

Beohut-Betts, J. (2005). Gender representations: 'Gender' in Africa. . In A. Cornwall (Ed.), Readings in gender in Africa. (pp. 20-25). London: International Africa Institute and James Currey.

Bradley, M. S. (2007). Girlfriends, wives, and strippers: Managing stigma in exotic dancer romantic relationships. Deviant Behavior, 28(4), 379-406.

Braun, V., \& Clarke, V. (2006). Using thematic analysis in psychology. Qualitative Research in Psychology, 3, 77-101.

Cornwall, A. (2005). Introduction: perspectives on gender in Africa. London: International Africa Institute and James Currey.

Fleming, P. J., Barrington, C., Perez, M., Donastorg, Y., \& Kerrigan, D. (2015). Strategies for recruiting steady male partners of female sex workers for HIV research. AIDS and Behavior, 19(2), 362-368.

Goldenberg, S. M., Cruz, M. G., Strathdee, S. A., Nguyen, L., Semple, S. J., \& Patterson, T. L. (2010). Correlates of unprotected sex with female sex workers among male clients in Tijuana, Mexico. Sexually Transmitted Diseases, 37(5), 319-324.

Harrison, A., O'sullivan, L. F., Hoffman, S., Dolezal, C., \& Morrell, R. (2006). Gender role and relationship norms among young adults in South Africa: measuring the context of masculinity and HIV risk. Journal of Urban Health, 83(4), 709722.

Jackson, L. A., Augusta-Scott, T., Burwash-Brennan, M., Karabanow, J., Robertson, K., \& Sowinski, B. (2009). Intimate relationships and women involved in the 
sex trade: perceptions and experiences of inclusion and exclusion. Health, 13(1), 25-46.

Jewkes, R., \& Morrell, R. (2010). Gender and sexuality: emerging perspectives from the heterosexual epidemic in South Africa and implications for HIV risk and prevention. Journal of the International AIDS society, 13(1), 6.

Jewkes, R., Sikweyiya, Y., Morrell, R., \& Dunkle, K. (2011). The relationship between intimate partner violence, rape and HIV amongst South African men: a crosssectional study. PLoS One, 6(9), e24256.

Kalichman, S. C., Klein, S. J., Kalichman, M. O., O'Connell, D. A., Freedman, J. A., Eaton, L., \& Cain, D. (2007). HIV/AIDS case managers and client HIV status disclosure: Perceived client needs, practices, and services. Health \& Social Work, 32(4), 259-267.

Kerrigan, D., Kennedy, C. E., Cheng, A. S., Sandison, S. J., Fonner, V. A., Holtgrave, D. R., \& Brahmbhatt, H. (2015). Advancing the strategic use of HIV operations research to strengthen local policies and programmes: the Research to Prevention Project. Journal of the International AIDS Society, 18(1).

Kimmel, M. (2001). Masculinities and femininities. Oxford: Pergamon.

Mahajan, A. P., Sayles, J. N., Patel, V. A., Remien, R. H., Ortiz, D., Szekeres, G., \& Coates, T. J. (2008). Stigma in the HIV/AIDS epidemic: a review of the literature and recommendations for the way forward. AIDS, 22(Suppl 2), S67.

Matovu, J., \& Ssebadduka, N. (2014). Knowledge, attitudes and barriers to condom use among female sex workers and truck drivers in Uganda: a mixed-methods study. African Health Sciences, 13(4), 1027-1033.

Murray, L., Moreno, L., Rosario, S., Ellen, J., Sweat, M., \& Kerrigan, D. (2007). The role of relationship intimacy in consistent condom use among female sex workers and their regular paying partners in the Dominican Republic. AIDS and Behavior, 11(3), 463-470.

Nyanzi, S., Nyanzi-Wokholi, B., \& Kalina, B. (2008). Male promiscuity: the negotiation of masculinities by motorbike taxi-riders in Masaka, Uganda. Men and Masculinities.

Parikh, S. A. (2007). The political economy of marriage and HIV: the ABC approach,"safe" infidelity, and managing moral risk in Uganda. American Journal of Public Health, 97(7), 1198-1208.

Rekart, M. L. (2006). Sex-work harm reduction. The Lancet, 366(9503), 2123-2134.

Rutakumwa, R., Mbonye, M., Kiwanuka, T., Bagiire, D., \& Seeley, J. (2015). Why do men often not use condoms in their relationships with casual sexual partners in Uganda? Culture, Health \& Sexuality, 17(10), 1237-1250.

Sanders, T. (2008). Male Sexual Scripts Intimacy, Sexuality and Pleasure in the Purchase of Commercial Sex. Sociology, 42(3), 400-417.

Scorgie, F., Chersich, M. F., Ntaganira, I., Gerbase, A., Lule, F., \& Lo, Y.-R. (2012). Socio-demographic characteristics and behavioral risk factors of female sex workers in sub-saharan Africa: a systematic review. AIDS and Behavior, 16(4), 920-933.

Silberschmidt, M. (2001). Disempowerment of men in rural and urban East Africa: implications for male identity and sexual behavior. World Development, 29(4), 657-671.

Simbayi, L. C., Kalichman, S. C., Strebel, A., Cloete, A., Henda, N., \& Mqeketo, A. (2007). Disclosure of HIV status to sex partners and sexual risk behaviours 
among HIV-positive men and women, Cape Town, South Africa. Sexually Transmitted Infections, 83(1), 29-34.

Siu, G. E., Seeley, J., \& Wight, D. (2013). Dividuality, masculine respectability and reputation: how masculinity affects men's uptake of HIV treatment in rural eastern Uganda. Social Science \& Medicine, 89, 45-52.

Siu, G. E., Wight, D., \& Seeley, J. (2014). 'Dented'and 'Resuscitated'masculinities: The impact of HIV diagnosis and/or enrolment on antiretroviral treatment on masculine identities in rural eastern Uganda. SAHARA-Journal, 11(1), 211221.

Syvertsen, J. L., Bazzi, A. R., Martinez, G., Rangel, M. G., Ulibarri, M. D., Fergus, K. B., Amaro, H., \& Strathdee, S. A. (2015). Love, trust, and HIV risk among female sex workers and their intimate male partners. American Journal of Public Health, 105(8), 1667-1674.

Syvertsen, J. L., Robertson, A. M., Palinkas, L. A., Rangel, M. G., Martinez, G., \& Strathdee, S. A. (2013). 'Where sex ends and emotions begin': Iove and HIV risk among female sex workers and their intimate, non-commercial partners along the Mexico-US border. Culture, Health \& Sexuality, 15(5), 540-554.

Syvertsen, J. L., Robertson, A. M., Rolón, M. L., Palinkas, L. A., Martinez, G., Rangel, M. G., \& Strathdee, S. A. (2013). "Eyes that don't see, heart that doesn't feel": Coping with sex work in intimate relationships and its implications for HIV/STI prevention. Social Science \& Medicine, 87, 1-8.

UNAIDS. (2014). Fast-track: ending the AIDS epidemic by 2030. Geneva: UNAIDS.

Vanwesenbeeck, I. (2001). Another decade of social scientific work on sex work: a review of research 1990-2000. Annual Review of Sex Research, 12(1), 242289.

Wamoyi, J., Fenwick, A., Urassa, M., Zaba, B., \& Stones, W. (2011). “Women's bodies are shops": Beliefs about transactional sex and implications for understanding gender power and HIV prevention in Tanzania. Archives of Sexual Behavior, 40(1), 5-15.

Warr, D. J., \& Pyett, P. M. (1999). Difficult relations: sex work, love and intimacy. Sociology of Health \& IIIness, 21(3), 290-309.

Wojcicki, J. M., \& Malala, J. (2001). Condom use, power and HIV/AIDS risk: sexworkers bargain for survival in Hillbrow/Joubert Park/Berea, Johannesburg. Social Science \& Medicine, 53(1), 99-121.

Wolff, B., Blanc, A. K., \& Gage, A. J. (2000). Who decides? Women's status and negotiation of sex in Uganda. Culture, Health \& Sexuality, 2(3), 303-322.

Wyrod, R. (2008). Between Women's Rights and Men's Authority Masculinity and Shifting Discourses of Gender Difference in Urban Uganda. Gender \& Society, 22(6), 799-823.

Wyrod, R. (2011). Masculinity and the persistence of AIDS stigma. Culture, Health \& Sexuality, 13(04), 443-456. 